\title{
We're In This Together: The Role of Team Characteristics in Enterprise Process Execution and Performance
}

\author{
Akshay Bhagwatwar \\ Northern Illinois University \\ abhagwatwar@niu.edu
}

\author{
Hillol Bala \\ Indiana University \\ hbala@indiana.edu
}

\author{
Jordan Barlow \\ California State University, Fullerton \\ jobarlow@fullerton.edu
}

\begin{abstract}
Organizations face challenges after a new enterprise system (ES) implementation, including employee resistance and negative impacts on organizational outcomes. ESs are used by employees in coordination with their team members for executing business processes. Consequently, team characteristics are likely to play a critical role in influencing perceptions about effective process execution and performance when using ESs. Yet research has not investigated the influence of team characteristics, such as team coordination, shared mental models, and mutual trust, in overcoming challenges associated with process execution following a new ES implementation. We conducted a lab simulation to investigate the role of team characteristics to moderate the influence of process characteristics on team and process performance. We posit that even if teams initially perceive processes as complex, rigid, and radical, team characteristics can mitigate these perceptions and reduce their influence on performance outcomes.
\end{abstract}

\section{Introduction}

Recently, we have witnessed a fundamental shift in the way organizations enable and manage their business processes using enterprise systems (ESs) such as enterprise resource planning (ERP), supply chain management (SCM), and product lifecycle management (PLM) systems [1, 2]. Despite the recent slowdown in economies around the world, spending on ESs is expected to increase at a steady pace of $2-3 \%$ over the next five years [3]. The globalization of organizations and the highly dynamic market environment is further driving the digitization of enterprise business processes [3, 4].

Prior research has suggested that employees perceive that these systems make business processes complex and rigid [3,5]. There is ample evidence in both research and practitioner literatures that implementation of ESs fail due to employee resistance, avoidance, and/or perfunctory use $[6,7,8]$. In many cases, employees are not able to realize any benefits of ESs and often face challenges related to effective business process execution [2]. Consequently, it takes time for organizations to realize intended benefits from these systems and associated business processes because employees find it difficult to execute such complex and rigid business processes $[1,6]$.

Although business processes are typically executed by teams of employees [9, 10, 11], there has been little or no research that examined process performance and its predictors at the team level. Consequently, a key question that has remained unexamined is whether team characteristics can help teams improve process performance even if the process is considered complex, rigid, and radically new following the implementation of an ES. In this research, we investigate how three key team characteristics - shared mental models, mutual trust, and implicit coordination - can help reduce the negative influence of process characteristics on process and team performance.

We used a lab-based simulation where undergraduate and graduate business school student teams executed a logistics business process using the SAP ERP system. The student teams executed the business process in a two-hour lab session that simulated two quarters of business activity. We collected perceptual data using surveys at different points during the session. Performance was measured at the team level using (a) logistics process performance, measured as the net profit earned by the team during the lab session, (b) perceived team effectiveness, and (c) perceived team performance. The results of data analyses supported all our hypotheses.

\section{Background}

A critical phase in regards to change management and mitigating the impact of new ES on employees has been referred to as shakedown phase in IS research $[12,13]$. This phase refers to the period of time when the ES is fully functional to the point when normal operation and regular use has been achieved [13, 14]. IS research has highlighted the criticality of this phase 
since employees start using the new ES and develop initial perceptions during this phase [8, 13, 15]. Common issues encountered during this phase are business disruptions, maintenance of old procedure or manual workarounds, system underuse or nonuse, and failure to achieve normal operations [16]. Employee reactions to the ES during this phase are critical for assessing the ES's effectiveness in meeting the intended objectives. Given the importance of employee perceptions to ES during the shakedown phase and the potential role of team characteristics in mitigating the associated challenges, we focus on individual and team reactions during this phase. The Technology Transitional Model (TTM) has been conceptualized to emphasize the value of a technology change that individuals perceive in organizations [15]. TTM suggests that even though a new ES implementation might pose numerous challenges, attitudes towards the ES would be influenced by the net value derived from the technology change [15]. Broadly, if an individual perceives that the new ES would be beneficial for his/her work, then the individual might approach the challenges associated with the change in a positive way. In this paper, we build on this foundation of TTM and focus on a set of team characteristics $[12,17,18]$ that drive changes in objective and perceptual measures of team process performance.

\section{Model and Hypotheses Development}

Figure 1 presents our research model. We posit that process characteristics negatively influence team and process performance outcomes in the context of ES business process execution. Prior research has conceptualized three key characteristics of an ES business process - process complexity, process rigidity, and process radicalness $[2,16]$. We define and discuss these characteristics in the following sections.

We propose a negative moderation effect where team characteristics mitigate the negative relationships between process characteristics and performance. We hypothesize that for high levels of a team's shared mental model, mutual trust, and implicit coordination, the negative influence of process characteristics on process and team performance will be weakened. Overall, despite the negative influence of a process that is complex, rigid, and radical, if the team can work well together during process execution, they can overcome the negative aspects of the processes and execute the process effectively as a team.

\subsection{Process Complexity and Performance}

Process complexity is the degree to which an employee believes that elements of his or her work processes (i.e., activities, information and resource requirements) are difficult to understand and act upon $[2,16]$. ESs help and support organizational business processes and are composed of a sequence of coordinated activities that are typically executed by a team of employees responsible for it. In addition, ESs are multi-module systems that integrate different business functions [16, 19]. Consequently, ESs are complex in terms of the hierarchy of organizational processes that they support. For example, on SAP ERP System, a popular ES solution, execution of a purchase order typically involves a sequence of many processes such as creation of a purchase order, goods receipt, invoice receipt from vendor, and accounts payable. Each part of the process in itself might have multiple steps. For example, for creation of a business process on SAP ERP System, the employee has to do steps such as article specification, vendor specification, quantity and cost determination for each article, specifying vendor allowances and discounts, automating vendor account determination, etc. Cumulatively, each business process forms a complex sequence of activities that the employee has to execute on the ES, in most cases, in coordination with other employees and/or stakeholders [19]. Consequently, this requires the employee to have access to a vast amount of information and/or resources.

After a new ES implementation, employees may experience a significant change in the sequence of activities required for execution of the business processes that they are responsible for [16]. If the ES makes it difficult for team members to access the information and resources needed for business process execution, they would find it difficult to complete the business process efficiently. This may have negative financial implications for the associated business process. As noted earlier, since these processes are executed by teams, the team would perceive that they have not been able to complete their work efficiently.

H1: Process complexity negatively influences process and team performance following an ES implementation.

\subsection{Process Rigidity and Performance}

Process rigidity is the degree to which an employee believes that elements of his or her work processes (i.e., activities, information and resource requirements) cannot be modified or circumvented during the course of executing the work processes [2, $16,19]$. Each ES is designed in a unique way and often does not resemble the existing sequence of activities in an organization [20,21]. Prior research has suggested 
that due to this mismatch between the organizational business processes and the ES, employees will perceive the new business processes to be inflexible [2, 16, 20]. For example, if an employee is used to a certain sequence of activities for the execution of a purchase order, it is likely that the employee would have to follow a difference sequence of activities and might have to follow a new set of protocols to execute purchase orders. Even if the employee can customize parts of the tasks, he/she will find the new process to be rigid since he/she might experience information and resource requirements during process execution.

Rigid processes pose a challenge to employees since they have no option but to get accustomed to processes on the the new ES as is [21, 22, 23]. For example, during collaboration on a logistics process, if teams wish to change the sequence of certain activities, they would not be able to do so if the processes are rigid. This will be perceived as a limitation by the team in completing their work. Since the processes on the new ES are inflexible, teams would have to find a way of completing the business process execution following the activity sequence on the new ES. Teams would need time to get acquainted with the new ES and would feel that their team performance is being negatively impacted. Since they have no option but to get used to the new ES, they would perceive that their performance has been sub-par with the new ES.

H2: Process rigidity negatively influences process and team performance following an ES implementation.

\subsection{Process Radicalness and Performance}

Process radicalness is the extent to which an employee believes that there is a degree of newness in the elements of his or her work processes (i.e., activities, information, and resource requirements) [2, $16,22]$. When organizations implement a new ES, it is usual for employees to perceive their business processes to have major changes in terms of new sequence of tasks, new tasks, or different information and resource requirements, as compared to the previous ES [20, 21]. Consequently, new ES implementations often lead to work processes that are unfamiliar; teams need time and effort to get accustomed to such processes [20, 23].

We posit that process radicalness has a negative influence on business process performance. When employee teams work on a new ES, they might face difficulties getting accustomed to the new processes. They will feel that the new process is challenging and has too many new elements. Instead of focusing on the task and getting the work completed, employee teams would struggle with the new elements of the processes.
They might struggle to find the right information and resources needed to complete their work. Consequently, during the shakedown phase, when employees are still getting accustomed to new business processes, performance would be negatively impacted. Employees might spend more time figuring out where to find the information needed for their work and as a result, might not be able to complete their work on time. As a result, teams might feel that their work performance has not been good with the new ES. Consequently, the team might perceive that they have not been effective at their work.

H3: Process radicalness negatively influences process and team performance following an ES implementation.

\subsection{Effect of Shared Mental Models}

A shared mental model, in the context of organizational business processes, is the organized understanding of relevant knowledge about the business processes that is acquired and maintained by the team for efficient task execution [24, 25]. Prior research has investigated shared mental model as a supporting and coordinating mechanism during teamwork [12, 24, 26]. A shared mental model is considered to be required for setting team goals, formulating team strategies, delegation of team tasks, monitoring of the team processes, and effective communication [24, 26, 27, 28].

Prior research has investigated shared mental models as a precursor to effective team collaboration $[28,18]$. Teams that have a shared understanding of their work on the new ES should be able to accomplish the work without many roadblocks [29, 18]. Even if they face challenges, team members should be able to find a resolution to issues via deliberation. When teams have an effective shared mental model, team members have a clear understanding of the tasks they have been assigned and complete those tasks as part of their decided team strategy. Even if teams perceive the process to be complex, since there is a clear understanding and communication among the team on what tasks each member has to perform, they would be able to complete the work without many issues. Similarly, for rigid processes, the team would have a clear strategy on how to execute the inflexible processes through coordination with each other. This will help them overcome the issues of inflexibility in the process sequence and enable them to coordinate with each other to accomplish successful process execution. Similarly, for a radical ES process, having a shared understanding of the process would facilitate task execution. Prior to task execution, team members would share their opinion on how to handle the new 
processes and decide on a clear strategy on how to execute the process. This will help reduce the negative impact of process radicalness and help teams to be effective during process execution.

H4: A team's shared mental model will negatively moderate the influence of process characteristics on process and team performance such that for high levels of shared mental model between team members the negative influence of process characteristics on performance outcomes would be reduced.

\subsection{Effect of Mutual Trust}

The criticality of mutual trust for a team to be efficient at work has been investigated in prior research in a variety of task contexts and types of teamwork [18, 29]. Lack of mutual trust leads to team members spending unnecessary time and effort in protecting, checking, and inspecting each other and each other's behaviors [29, 30, 31]. This negatively influences any constructive collaboration that the teams can achieve in that time. Typically, in organizations, it is expected that team members would work independently for some time before sharing their relevant findings with the team. Consequently, there is a certain level of inherent risk that team members have to accept when relying on each other to complete work and meet work deadlines. Mutual trust refers to the shared perception and understanding within a team that team members will perform particular actions important to its members and will recognize and protect the rights and interests of everyone [30, 32]. Teams with a high level of mutual trust share useful information with no hesitation [29, 32]. In addition, members of such teams also feel confident about the accuracy of information and do not feel the necessity to verify its authenticity.

We posit that mutual trust should play a key role in mitigating the influence of process characteristics on performance outcomes. For team members that have high levels of mutual trust, it can be expected that the members would rely on the information shared by other members without verifying the information's source. This is critical for employees that are already struggling with the challenges posed by the new ES. With mutual trust, even if employees struggle with a complex, rigid, or radical business process, they can rely on their colleagues to help them overcome any roadblocks faced during process execution. Team members would feel comfortable taking guidance from others regarding use of the new ES and hence would be able to resolve any difficulties associated with the new processes. Consequently, such teams would be able to perform well on work tasks and achieve the desired performance outcomes. When employees encounter complex processes on an ES, they would trust their team members and would not hesitate to ask for help or suggestions for process execution. This will facilitate process execution and help the team to be effective.

H5: Mutual trust will negatively moderate the influence of process characteristics on performance outcomes such that for high levels of mutual trust between team members the negative influence of process characteristics on performance outcomes would be reduced.

\subsection{Effect of Implicit Coordination}

Past research in management related to team coordination focused on planning and communication as key mechanisms [18, 33]. Recent work suggests that implicit coordination between team members involves use of strategies and behavior patterns aimed at integrating and aligning the actions, knowledge, and objectives of interdependent members, with a view to achieving common goals [33, 34]. Implicit coordination refers to the actions that individual team members take in response to the needs of other team members and task demands [18, 34]. In a team that is effectively coordinating, members adjust their behavior to deliver to others' needs, without having to communicate directly with each other or explicitly plan the activity [35, 36]. For example, when executing a business process as a team, individual members often make assumptions about the anticipated needs of other members based on their past experience with the members, past behavior, and expertise. Consequently, adapting their behavior by anticipating the needs of others facilitates effective completion of team tasks.

Since ESs involve processes that require team effort and communication of important information between the team, implicit coordination will facilitate the execution of processes [33]. If all team members are able to anticipate needs of other members and adjust their work accordingly, teams will perceive that they were effective in their work [36]. In teams with high levels of implicit coordination, team members are able to monitor each other's progress and provide assistance to others when needed. Consequently, such teams will overcome challenges related to the processes on ES being complex, rigid, and radical. As a result, such teams would be able to perform well.

H6: Implicit coordination will negatively moderate the influence of process characteristics on performance outcomes such that for high levels of mutual trust between team members the negative influence of process characteristics on performance outcomes would be reduced.

\section{Methodology}




\subsection{Participants and Procedures}

A lab-based simulation was used for the study. 254 undergraduate and graduate level students from a large business school in the USA participated, working in 66 teams of four students each. The study was conducted as part of the coursework for courses related to enterprise systems. 58 percent of participants were male and the average age was 21.2 years.

The study was set up as a two-hour lab session during which students executed a logistics business process on SAP ERP using ERPSim. The goal of the logistics process for students was to work as a team to complete the transfer of different types of goods from the warehouse of a fictitious company to store locations for that company. Next, the students had to collaboratively design a pricing strategy for in-store goods with the goal of maximizing sales and increasing profitability. The eventual goal was not only to successfully execute the business process with their team but also to collaborate and strategize the process so that team profits could be maximized.

As noted in Figure 1, data was collected at three points of time during the session using three different surveys that consisted of measures related to the constructs in the figure. First, team members were seated together and provided detailed handouts on their roles during the session. Each team member was assigned one of four specific roles as part of the logistics process - planning manager, pricing manager, transfer manager, and sales manager. Next, students were provided training on the logistics process and the use of SAP ERP for the execution of the process. As part of the logistics process, it was important that each of the four members would execute the specific business processes associated with their role. Next, the students completed a trial round of process execution so that they could get an understanding of the logistics process and the role. At this point (T1), students were asked to complete survey 1 consisting of perceptual measures related to process characteristics - process complexity, process rigidity, and process radicalness.

Next, the ERPSim simulation was started where students had to perform the business process with their team for 10 days (each day simulated as 90 seconds on ERPSim). The 10 days cumulatively constituted one quarter of business activity. At the end of this period (T2), students individually completed survey 2, consisting of perceptual measures related to team characteristics - shared mental models, mutual trust, and implicit coordination. Next, students were given a 10-minute break to discuss the business process execution strategy with their team and to make any necessary changes to their strategy. Next, teams completed another round of simulation, again 10 days with each day simulated as 90 seconds (Quarter 2). At the end of this period (T3), students completed another survey consisting of the perceptual performance measures - team effectiveness and team performance. After completion of the survey, students were shown the final simulation results with details such as net profit and net sales. Students were then debriefed and the session concluded.

\subsection{Measures}

We used pre-validated items for constructs published in prior research (see Table 1 for details). Team performance on business processes was measured using three variables - perceived team performance, perceived team effectiveness (see Table 1 for measurement items), and process performance, measured as the net profit the teams were able to achieve during the lab session. Our objective in using these three performance measures was to capture the team's perceptions regarding their performance and also the objective performance obtained from the ERP SAP. Although there may be some overlap in these constructs, cumulatively, the three measures provide a comprehensive understanding of the team's performance on the logistics process task.

\section{Results}

All constructs were aggregated to the team level. SEM was used to perform structural and measurement model analysis simultaneously. Measurement model analysis validated psychometric properties of measures. Structural model analysis examined nomological networks in structural model. Survey data was analyzed using Amos 22.0. Results (table 3) show that process complexity, rigidity, and radicalness negatively influenced process performance, team effectiveness, and team performance, thus supporting $\mathrm{H} 1, \mathrm{H} 2$, and $\mathrm{H} 3$. These results conform to the findings of prior research related to the negative influence of process characteristics [2]. Moderation hypotheses related to team characteristics $(\mathrm{H} 4, \mathrm{H} 5, \mathrm{H} 6)$ were supported, implying that team characteristics reduced the negative influence of process characteristics on process performance and team performance.

Moderation effect of mutual trust on influence of process rigidity on process performance was not significant. We speculate that a potential reason is the nature of the mutual trust construct (as compared to implicit coordination and shared mental model). Implicit coordination relates to communication of information during process execution while shared mental model refers to development of common 
knowledge about the process during process execution. Consequently, both constructs are team characteristics that directly influence execution of the business process. In contract, mutual trust relates to the level of trust during communication of information related to business processes (not impacting process execution directly). It is possible that teams with low mutual trust would still communicate information and work to execute business processes together. Consequently, mutual trust did not moderate the relationship between process rigidity and process performance.

Standard procedural and statistical remedies were followed to address common method bias. There were no significant indicators of common method bias. Due to space limitations, we have not included these details in this paper. Next, a confirmatory factor analysis (CFA) was conducted to validate psychometric properties of survey instrument. Results (Table 1) indicate that measurement model adequately fit the data. Psychometric properties were measured by (1) examining if measurement model had acceptable goodness of fit and (2) examining the unidimensionality, convergent and discriminant validity, and reliability. Goodness of fit was confirmed using threshold guidelines outlined by Hair et al. [38].

For measurement model, chi-square value was 2.146, below threshold of 3.0. Root mean square error of approximation (RMSEA) was 0.071 , below the 0.08 cutoff. Comparative fit index (CFI) (0.962) was above cutoff of 0.90. Convergent validity was evaluated using three standard criteria [38, 37] (1) all indicator factor loadings $(\lambda)$ exceeded the cutoff of 0.7 and were significant at $\mathrm{p}<0.05$, (2) composite reliabilities were higher than 0.7 , and (3) average variance extracted (AVE) for each construct exceeded the variance due to measurement error for that construct (see Table 1). Table 1 shows that all factor loadings in the CFA model exceeded 0.7 and were significant at $\mathrm{p}<0.001$. Discriminant validity was assessed using interconstruct correlations (see Table 2). Constructs were found to have a stronger correlation with their own measures than with other constructs. Correlations between constructs were less than the square root value of AVE, representing discriminant validity. Reliability was examined using Cronbach's alpha $(\alpha)$. Constructs had $\alpha$ of more than 0.8 , indicating a high reliability of items used for each construct in the survey.

GFI for the structural model was 2.421, below the threshold of 3.0. RMSEA was 0.069 , below the cutoff value of 0.08 . CFI was 0.934 , above the cutoff value of 0.90. Results of structural model analysis with path loadings for the relationships are shown in Table 3. Our model successfully explained dependent variables - process performance $\left(\mathrm{R}^{2}=0.259\right)$, team effectiveness $\left(\mathrm{R}^{2}=0.304\right)$, and team performance $\left(\mathrm{R}^{2}=0.268\right)$.

\section{Discussion}

Our objective was to understand the moderation effect of team characteristics on the relationship between process characteristics and performance. To investigate this, we conducted a research study using a lab-based simulation where teams executed a logistics process on SAP ERP. Results show that team characteristics play a key role in mitigating the negative influence of process characteristics on the performance outcomes. In this section, we discuss theoretical contributions and practical implications.

\subsection{Theoretical Contributions}

We contribute to research on role of process characteristics in ESs and addresses an important scientific gap related to impact of team characteristics on process and team performance. First, we identify team characteristics that reduce the negative influence of process characteristics on performance outcomes. IS research has highlighted the need to understand factors that reduce the negative impact of process characteristics on teams [16, 37]. As noted in prior research, process characteristics have negative emotional implications including job anxiety, job stress, and job dissatisfaction [37]. However, research has not investigated the positive influence of team characteristics in overcoming challenges associated with changes introduced by a new ES. Our work advances scientific understanding of how team factors can be investigated in specific work contexts (e.g., the logistics process that was central to this study).

Second, our research places team characteristics within the nomological network that captures the role of process characteristics in impacting performance for a new ES. This is important since business processes on ESs are executed by a team. Consequently, while the influence of process characteristics on individuals' work processes is important to investigate, the role of team characteristics cannot be ignored. Research has highlighted the need to examine factors that help employees overcome the emotional and work challenges during the shakedown phase [16]. Factors such as cumulative understanding of the team members about ES-supported business processes, coordination activities among team members in task execution, and level of trust when employees share information among each other are important in the context of organizational business processes. Consequently, our research highlights the importance of looking beyond technological and process-related factors that have implications on business process performance. 


\subsection{Practical Implications}

The findings of this study have several implications for practice. First, our findings indicate that organizations need to facilitate team collaboration during the execution of business processes on ESs. As indicated by the moderation effect of team characteristics in our model, it is important for organizations to ensure that team members are effectively able to share information and resources during the execution of business processes on a new ES. This will help individuals overcome challenges associated with the complexity of the processes on the new ES. Employees using a new ES during the shakedown phase might not be able to able to effectively execute their work tasks on the new ES, leading to negative performance implications. However, if they are able to get help from team members and coordinate task execution with them, then the challenges associated with the complexity, rigidity, and radicalness of the new processes can be mitigated. Consequently, such teams would be able to manage their work with the new system and perform well. Organizations can organize team events such as seminars and workshops that will enable team members to know each other and develop a sense of trust. It is also important for team members to understand each other's professional background and skillset. This will help them realize the expectations that their team members would have from them during business process execution. Such practices will help the team members develop a sense of rapport and ensure effective task execution.

Second, our research has implications for the design of ES solutions. As indicated in our model, given the important role of team characteristics, it is imperative for ESs to incorporate features that facilitate the development of team factors. ESs should facilitate information and resource sharing during business process execution. Support for knowledge repositories, document sharing, internal discussion forums to discuss common issues, instant messaging, and dynamic information feeds are examples of features that ESs could incorporate to facilitate team collaboration. Employees will undoubtedly face challenges while getting accustomed to the new ES. However, support for tools/features that help team members communicate and collaborate during business process execution can help team members overcome these challenges quickly, leading to positive implications on their performance.

\section{Conclusions}

Our work demonstrates the importance of facilitating team characteristics during the shakedown phase of new ES use. We address an important research gap of understanding the role of team characteristics during the shakedown phase by offering valuable insights on how team characteristics can help mitigate the impact of complexity, rigidity, and radicalness of business processes on team and process performance.

Our findings should be interpreted in light of certain limitations. First, as with any research study involving student subjects, this study has the potential of low external validity. However, given the aims and context of our study, student subjects were appropriate for testing the theory [40, 41]. Business students represent future users of ESs in real organizations and hence represent the appropriate target population for our study. Nonetheless, this remains a limitation. Future research should investigate our model with ES users from organizations.

Second, the simulation replicated work scenarios where collaboration is key for ES process execution. We acknowledge that team variables such as shared mental model, mutual trust, and implicit coordination require time and sustained team collaboration to develop. Although the simulation allowed the development of team characteristics as the individuals learnt and executed the ES processes, future research can extend our work by investigating real-life work scenarios using longitudinal data collection methods.

\section{References}

[1] H.W. Kim, and A. Kankanhalli, "Investigating user resistance to information systems implementation: A status quo bias perspective", MIS Quarterly, 2009, pp. 567-582.

[2] H. Bala, "The effects of IT-enabled supply chain process change on job and process outcomes: A longitudinal investigation," Journal of Operations Management, 31, 6, 2013, pp. 450-473.

[3] V. Woods, and R. van der Meulen, "Gartner Gartner Says Worldwide IT Spending is Forecast to Grow 0.6 Percent in 2016", 2016, http://www.gartner.com/newsroom/id/3186517

[4] J. Manyika, S. Lund, J. Bughin, J. Woetzel, K. Stamenov, and D. Dhingra, "Digital globalization: The new era of global flows", 2016, http://www.mckinsey.com/business-functions/mckinsey-digital/ourinsights/digital-globalization-the-new-era-of-global-flows

[5] H. Bala, and V. Venkatesh, "Adaptation to information technology: a holistic nomological network from implementation to job outcomes", Management Science, 62, 1, 2015, pp. 156-179.

[6] L. Lapointe, and S. Rivard, "A multilevel model of resistance to information technology implementation", MIS Quarterly, 2005, pp. $461-491$.

[7] A.O. De Guinea, and M.L. Markus, "Why break the habit of a lifetime? Rethinking the roles of intention, habit, and emotion in 
continuing information technology use", MIS Quarterly, 2009, pp. 433-444.

[8] M.G. Morris, and V. Venkatesh, "Job characteristics and job satisfaction: understanding the role of enterprise resource planning system implementation", MIS Quarterly, 2010, pp. 143-161.

[9] N. Mehta, D. Hall, and T. Byrd, "Information technology and knowledge in software development teams: The role of project uncertainty", Information \& Management, 51, 4, 2014, pp. 417-429.

[10] S.L. Jarvenpaa, and D.E. Leidner, "Communication and trust in global virtual teams", Journal of Computer-Mediated Communication, 3, 4, 1998, pp. 1-15.

[11] S.L. Jarvenpaa, T.R. Shaw, and D.S. Staples, "Toward contextualized theories of trust: The role of trust in global virtual teams", Information Systems Research, 15, 3, 2004, pp. 250-267.

[12] C. Duhigg, "What Google Learned From Its Quest to Build the Perfect Team," 2016 http://www.nytimes.com/2016/02/28/magazine/what-google-learnedfrom-its-quest-to-build-the-perfect-team.html

[13] L. Häkkinen, and O.P. Hilmola, "ERP evaluation during the shakedown phase: lessons from an after-sales division", Information Systems Journal, 18, 1, 2008, pp. 73-100.

[14] T.A. Sykes, V. Venkatesh, and A. Rai, "Explaining physicians' use of EMR systems and performance in the shakedown phase", Journal of the American Medical Informatics Association, 18, 2, 2011, pp. 125-130.

[15] R.O. Briggs, M. Adkins, D. Mittleman, J. Kruse, S. Miller, and J.F. Nunamaker, "A technology transition model derived from field investigation of GSS use aboard the USS Coronado," Journal of Management Information Systems, 15, 3, 1998, pp. 151-195.

[16] H. Bala, and V. Venkatesh, "Changes in employees' job characteristics during an enterprise system implementation: A latent growth modeling perspective", MIS Quarterly, 37, 4, 2013, pp. 11131140.

[17] D.M. Fisher, S.T. Bell, E.C. Dierdorff, and J.A. Belohlav, "Facet personality and surface-level diversity as team mental model antecedents: Implications for implicit coordination," Journal of Applied Psychology, 97, 4, 2012, pp. 825-841.

[18] A. Edmondson, "Psychological safety and learning behavior in work teams," Administrative science quarterly, 1999, pp. 350-383.

[19] R.E. Wood, "Task complexity: Definition of the construct", Organizational Behavior and Human Decision Processes, 37, 1, 1986, pp. 60-82.

[20] M.S. Feldman, and B.T. Pentland, "Reconceptualizing organizational routines as a source of flexibility and change", Administrative Science Quarterly, 48, 1, 2003, pp. 94-118.

[21] H. Bala, "Nothing endures but change: An investigation of the effects of enterprise systems implementation and business process changes on employees' work life", 2007, Proceedings of the 2007 Americas Conference on Information Systems, 383.

[22] A.E. Rafferty, and M.A. Griffin, "Perceptions of organizational change: a stress and coping perspective", Journal of Applied Psychology, 91, 5, 2006, pp. 1154-1162.
[23] H. Liang, N. Saraf, Q. Hu, and Y. Xue, "Assimilation of enterprise systems: the effect of institutional pressures and the mediating role of top management", MIS Quarterly, 2007, pp. 59-87.

[24] T.E. Johnson, Y. Lee, D.L. O'Connor, M.K. Khalil, and X. Huang, "Measuring sharedness of team-related knowledge: Design and validation of a shared mental model instrument," Human Resource Development International, 10, 4, 2007, pp. 437-454.

[25] S. Mohammed, and B.C. Dumville, "Team mental models in a team knowledge framework: Expanding theory and measurement across disciplinary boundaries", Journal of organizational Behavior, 22, 2, 2001, pp. 89-106

[26] E. Salas, D.E. Sims, and C.S. Burke, "Is there a "Big Five" in teamwork?", Small group research, 36, 5, 2005, pp. 555-599.

[27] R. Klimoski, and S. Mohammed, "Team mental model: Construct or metaphor?", Journal of management, 20, 2, 1994, pp. 403-437.

[28] P. Van den Bossche, W. Gijselaers, M. Segers, G. Woltjer, and P. Kirschner, "Team learning: building shared mental models", Instructional Science, 39, 3, 2011, pp. 283-301.

[29] K.M. Nelson, and J.G. Cooprider, "The contribution of shared knowledge to IS group performance," MIS Quarterly, 1996, pp. 409432.

[30] A.C. Costa, R.A. Roe, and T. Taillieu, "Trust within teams: The relation with performance effectiveness", European Journal of Work and Organizational Psychology, 10, 3, 2001, pp. 225-244.

[31] R.C. Mayer, J.H. Davis, and F.D. Schoorman, "An integrative model of organizational trust", Academy of Management Review, 20, 3, 1995, pp. 709-734.

[32] M.A. Serva, M.A. Fuller, and R.C. Mayer, "The reciprocal nature of trust: A longitudinal study of interacting teams", Journal of Organizational Behavior, 26, 6, 2005, pp. 625-648.

[33] R. Rico, M. Sánchez-Manzanares, F. Gil, and C. Gibson, "Team implicit coordination processes: A team knowledge-based approach", Academy of Management Review, 33, 1, 2008, pp. 163184 .

[34] A. Espinosa, F.J. Lerch, R.E. Kraut, E. Salas, and S.M. Fiore, "Explicit vs. implicit coordination mechanisms and task dependencies: one size does not fit all", Team cognition: understanding the factors that drive process and performance. American Psychological Association, Washington, DC, pp. 107-129.

[35] J.E. Mathieu, T.S. Heffner, G.F. Goodwin, E. Salas, and J.A. Cannon-Bowers, "The influence of shared mental models on team process and performance", Journal of Applied Psychology, 85, 2, 2000, pp. 273-283.

[36] J.A. Cannon-Bowers, and E. Salas, "Reflections on shared cognition", Journal of Organizational Behavior, 22, 2, 2001, pp. 195202.

[37] S.C. Srivastava, S. Chandra, and A. Shirish, "Technostress creators and job outcomes: theorising the moderating influence of personality traits", Information Systems Journal, 25, 4, 2015, pp. $355-401$.

[38] Hair, J. F., R.E. Anderson, R.L. Tatham, and W.C. Black, Multivariate data analysis, Prentice Hall International, NY, 1998. 
[39] C. Fornell, and D.F. Larcker, "Evaluating structural equation models with unobservable variables and measurement error," Journal of marketing research, 1981, pp. 39-50.

[40] D. Compeau, B. Marcolin, H. Kelley, and B.A. Nijstad, "Research commentary-generalizability of information systems research using student subjects-a reflection on our practices and recommendations for future research," Information Systems Research, 23, 4, 2012, pp. 1093-1109.
[41] A.S. Lee, and R.L. Baskerville, "Generalizing Generalizability in Information Systems Research," Information Systems Research, 14, 3, 2003, pp. 221-243.

[42] A. Chang, and P. Bordia, "A multidimensional approach to the group cohesion-group performance relationship," Small Group Research, 32, 4, 2001, pp. 379-405.

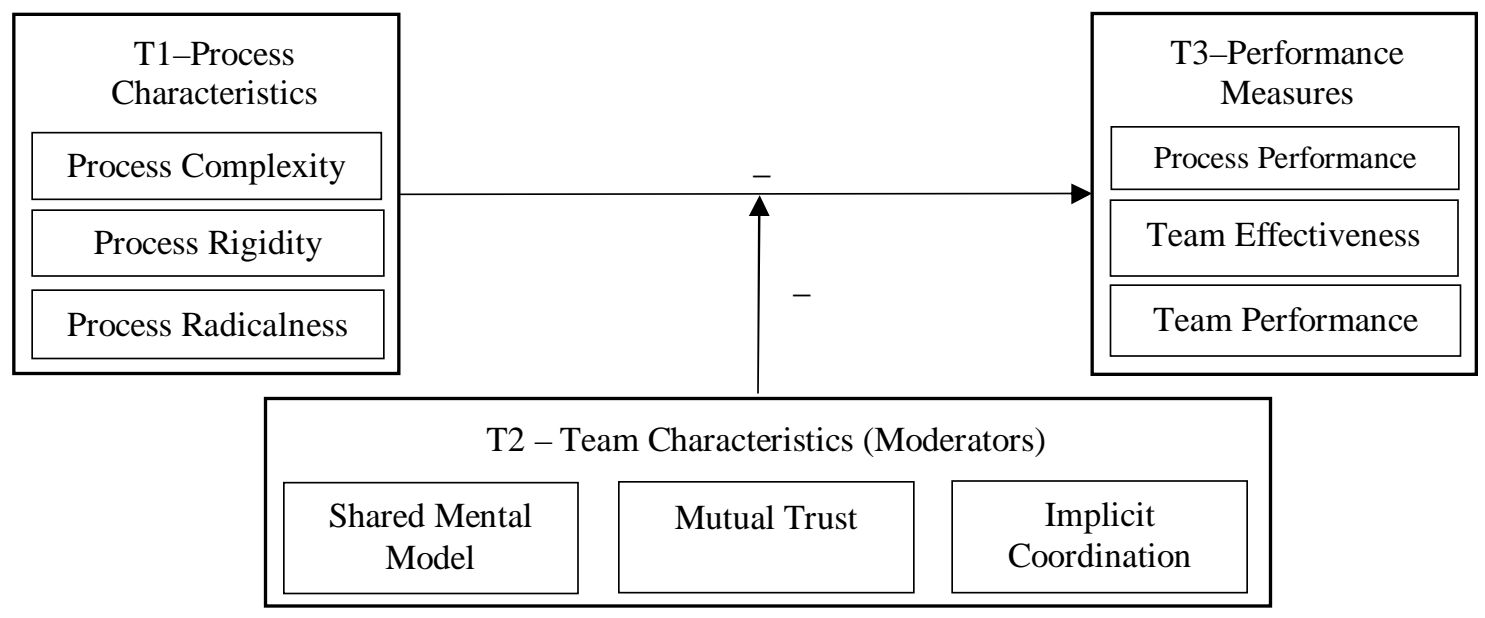

Figure 1: Research model

Table 1. Results of measurement model analysis

\begin{tabular}{|c|c|c|c|c|c|}
\hline Construct & Measurement Items & $\lambda$ & $\boldsymbol{\alpha}$ & CR & AVE \\
\hline \multirow{4}{*}{$\begin{array}{l}\text { Process } \\
\text { Complexity } \\
\text { (Adapted } \\
\text { from [18]) }\end{array}$} & $\begin{array}{l}\text { It is often difficult to understand what resources I may need to execute the } \\
\text { logistics process. }\end{array}$ & .842 & \multirow[t]{4}{*}{.882} & \multirow[t]{4}{*}{.892} & \multirow[t]{4}{*}{.707} \\
\hline & $\begin{array}{l}\text { There is no understandable sequence of steps that can be followed in executing } \\
\text { the logistics process. }\end{array}$ & .851 & & & \\
\hline & $\begin{array}{l}\text { It is often difficult to understand what information I may need for the logistics } \\
\text { process. }\end{array}$ & .846 & & & \\
\hline & It is often difficult to predict the steps of the logistics process. & .823 & & & \\
\hline \multirow{4}{*}{$\begin{array}{l}\text { Process } \\
\text { Rigidity } \\
\text { (Adapted } \\
\text { from [2]) }\end{array}$} & The logistics process is so inflexible that it follows a fixed set of steps. & .862 & \multirow[t]{4}{*}{.869} & \multirow[t]{4}{*}{.858} & \multirow[t]{4}{*}{.705} \\
\hline & There is no variation in the sequence of the logistics process tasks. & .846 & & & \\
\hline & The logistics process is not flexible. & .801 & & & \\
\hline & Overall, the logistics process is very rigid. & .826 & & & \\
\hline \multirow{3}{*}{$\begin{array}{l}\text { Process } \\
\text { Radicalness } \\
\text { (Adapted } \\
\text { from [2]) }\end{array}$} & $\begin{array}{l}\text { The logistics process tasks now seem to be very different from what I } \\
\text { previously perceived. }\end{array}$ & 912 & \multirow[t]{3}{*}{.867} & \multirow[t]{3}{*}{.876} & \multirow[t]{3}{*}{.803} \\
\hline & The tasks of the logistics process now seem radically different. & .893 & & & \\
\hline & $\begin{array}{l}\text { Overall, I feel that the logistics process is very different from what I initially } \\
\text { thought. }\end{array}$ & .884 & & & \\
\hline \multirow{5}{*}{$\begin{array}{l}\text { Shared } \\
\text { Mental } \\
\text { Model } \\
\text { (Adapted } \\
\text { from [24]) }\end{array}$} & It was clear from the beginning what this team had to accomplish. & .821 & \multirow[t]{5}{*}{.895} & \multirow[t]{5}{*}{911} & \multirow[t]{5}{*}{.714} \\
\hline & $\begin{array}{l}\text { This team spent time making sure every team member understood the team } \\
\text { objectives. }\end{array}$ & .841 & & & \\
\hline & $\begin{array}{l}\text { Team members understood what was expected of them in their respective } \\
\text { roles. }\end{array}$ & .845 & & & \\
\hline & $\begin{array}{l}\text { Shortly after the start this team had a common understanding of the task we } \\
\text { had to handle. }\end{array}$ & .827 & & & \\
\hline & Shortly after the start this team had a common understanding of how to deal & .868 & & & \\
\hline
\end{tabular}




\begin{tabular}{|c|c|c|c|c|c|}
\hline & with the task. & & & & \\
\hline \multirow{4}{*}{$\begin{array}{l}\text { Mutual Trust } \\
\text { (Adapted } \\
\text { from [17]) }\end{array}$} & In our team we can rely on each other to get the job done. & 864 & \multirow[t]{4}{*}{.849} & \multirow[t]{4}{*}{.882} & \multirow[t]{4}{*}{.738} \\
\hline & Members of this team are able to bring up problems and tough issues. & .838 & & & \\
\hline & $\begin{array}{l}\text { No one in this team would deliberately act in a way that undermines my } \\
\text { efforts. }\end{array}$ & .861 & & & \\
\hline & $\begin{array}{l}\text { Working with members of this team, my unique skills and talents are valued } \\
\text { and utilized. }\end{array}$ & .874 & & & \\
\hline \multirow{4}{*}{$\begin{array}{l}\text { Implicit } \\
\text { Coordination } \\
\text { (Adapted } \\
\text { from [18]) }\end{array}$} & $\begin{array}{l}\text { Members of my team provided task-related information to other members } \\
\text { without being asked. }\end{array}$ & .882 & \multirow[t]{4}{*}{.824} & \multirow[t]{4}{*}{.867} & \multirow[t]{4}{*}{.775} \\
\hline & My team proactively helped individual members when they needed assistance. & .904 & & & \\
\hline & My team monitored the progress of all members' performance. & 871 & & & \\
\hline & $\begin{array}{l}\text { Members of my team effectively adapted their behavior to the actions of other } \\
\text { members. }\end{array}$ & .863 & & & \\
\hline \multirow{3}{*}{$\begin{array}{l}\text { Team } \\
\text { Effectiveness } \\
\text { ([42]) }\end{array}$} & I am satisfied with the performance of my team. & .874 & \multirow[t]{3}{*}{.874} & \multirow[t]{3}{*}{.804} & \multirow[t]{3}{*}{.724} \\
\hline & We have completed the task in a way we all agreed upon. & .861 & & & \\
\hline & I would want to work with this team in the future. & .818 & & & \\
\hline \multirow{3}{*}{$\begin{array}{l}\text { Team } \\
\text { Performance } \\
\text { ([29]) }\end{array}$} & This team met or exceeded task requirements. & .912 & \multirow[t]{3}{*}{.852} & \multirow[t]{3}{*}{.815} & \multirow[t]{3}{*}{.809} \\
\hline & This team did superb work. & .908 & & & \\
\hline & This team kept getting better and better while performing the assigned task. & .879 & & & \\
\hline
\end{tabular}

(Note: $\lambda=$ factor loading, $\alpha=$ Cronbach's alpha $C R=$ Composite Reliability, AVE $=$ Average Variance Extracted)

Table 2. Correlation Matrix

\begin{tabular}{|l|l|l|l|l|l|l|l|l|l|l|l|}
\hline & Mean & SD & PCOM & PRGD & PRAD & SMM & MTRU & COOR & TEFF & TPER & PROP \\
\hline PCOM & 5.32 & 0.82 & .840 & & & & & & & & \\
\hline PRGD & 5.11 & 0.72 & $.178^{* *}$ & .834 & & & & & & & \\
\hline PRAD & 4.74 & 1.21 & $.191^{* *}$ & $.187^{* *}$ & .896 & & & & & & \\
\hline SMM & 4.69 & 1.04 & $.104^{*}$ & $.126^{*}$ & $.114^{*}$ & .845 & & & & & \\
\hline MTRU & 4.52 & 1.37 & $.127^{*}$ & $.134^{*}$ & $.126^{*}$ & $.304^{* * *}$ & .859 & & & & \\
\hline COOR & 4.94 & 1.26 & $.118^{*}$ & $.106^{*}$ & $.131^{*}$ & $.252^{* *}$ & $.341^{* * *}$ & .880 & & & \\
\hline TEFF & 4.58 & 0.94 & $-.182^{* *}$ & $-.204^{* *}$ & $-.264^{* *}$ & $.276^{* *}$ & $.204^{* *}$ & $.322^{* * *}$ & .851 & & \\
\hline TPER & 4.86 & 0.76 & $-.173^{* *}$ & $-.198^{* *}$ & $-.241^{* *}$ & $.243^{* *}$ & $.271^{* * *}$ & $.309^{* * *}$ & $.421^{* * * *}$ & .899 & \\
\hline PROP & 18623.32 & 9857.04 & $-.221^{* *}$ & $-.169^{*}$ & $-.196^{* *}$ & $.328^{* * *}$ & $.283^{* * *}$ & $.264^{* *}$ & $.389^{* * * *}$ & $.342^{* * *}$ & - \\
\hline
\end{tabular}

Note: $S D=$ Standard Deviation, PCOM = Process Complexity, $P R G D=$ Process Rigidity, PRAD = Process Radicalness, SMM = Shared Mental Model, $M T R U=$ Mutual Trust, COOR = Implicit Coordination, TEFF $=$ Team Effectiveness, TPER $=$ Team Performance, PROP $=$ Process Performance. The values in the diagonal of the table represent the square root of AVE (Average Variance Extracted).

Table 3. SEM Results

\begin{tabular}{|c|c|c|c|c|}
\hline & & $\begin{array}{c}\text { Process } \\
\text { Performance }\end{array}$ & $\begin{array}{c}\text { Team } \\
\text { Effectiveness }\end{array}$ & $\begin{array}{c}\text { Team } \\
\text { Performance }\end{array}$ \\
\hline \multirow{2}{*}{$\begin{array}{c}\text { Control } \\
\text { Variables } \\
\end{array}$} & Age & 0.08 & -0.02 & 0.05 \\
\hline & Computer Self-Efficacy & 0.04 & 0.03 & -0.06 \\
\hline \multirow{3}{*}{$\begin{array}{l}\text { Independent } \\
\text { Variables }\end{array}$} & Process Complexity & $-0.212 * *$ & $-0.262 * * *$ & $-0.169^{*}$ \\
\hline & Process Rigidity & $-0.176^{*}$ & $-0.192 * *$ & $-0.216^{* *}$ \\
\hline & Process Radicalness & $-0.189 * *$ & $-0.206 * *$ & $-0.193 * *$ \\
\hline \multirow{9}{*}{$\begin{array}{l}\text { Moderation } \\
\text { Effect }\end{array}$} & Shared Mental Model x Process Complexity & $0.191 * *$ & $0.173^{*}$ & $0.236 * *$ \\
\hline & Shared Mental Model x Process Rigidity & $0.231 * *$ & $0.214 * *$ & $0.219 * *$ \\
\hline & Shared Mental Model x Process Radicalness & $0.246 * *$ & $0.182 * *$ & $0.184 * *$ \\
\hline & Mutual Trust x Process Complexity & $0.224 * *$ & $0.166^{*}$ & $0.197 * *$ \\
\hline & Mutual Trust x Process Rigidity & 0.113 & $0.241 * *$ & $0.162 *$ \\
\hline & Mutual Trust x Process Radicalness & $0.189 * *$ & $0.189 * *$ & $0.205^{* *}$ \\
\hline & Implicit Coordination x Process Complexity & $0.172 *$ & $0.228 * *$ & 0.103 \\
\hline & Implicit Coordination x Process Rigidity & $0.193 * *$ & $0.281 * * *$ & $0.177^{*}$ \\
\hline & Implicit Coordination x Process Radicalness & $0.291 * * *$ & $0.243 * *$ & $0.212 * *$ \\
\hline $\mathbf{R}^{2}$ & & 0.259 & 0.304 & 0.268 \\
\hline
\end{tabular}

